\title{
Circadian Posttranscriptional Regulatory Mechanisms in Mammals
}

\author{
Carla B. Green \\ Department of Neuroscience, University of Texas Southwestern Medical Center, Dallas, Texas 75390-9111 \\ Correspondence: carla.green@utsouthwestern.edu
}

The circadian clock drives rhythms in the levels of thousands of proteins in the mammalian cell, arising in part from rhythmic transcriptional regulation of the genes that encode them. However, recent evidence has shown that posttranscriptional processes also play a major role in generating the rhythmic protein makeup and ultimately the rhythmic physiology of the cell. Regulation of steps throughout the life of the messenger RNA (mRNA), ranging from initial mRNA processing and export from the nucleus to extensive control of translation and degradation in the cytosol have been shown to be important for producing the final rhythms in protein levels critical for proper circadian rhythmicity. These findings will be reviewed here.

$I_{\mathrm{c}}^{\mathrm{n}}$ n mammals, cell-autonomous circadian clocks control rhythmic expression of thousands of messenger RNAs (mRNAs), ultimately generating daily rhythms in biochemistry, physiology, and behavior (Pittendrigh 1981a,b; Akhtar et al. 2002; Panda et al. 2002; Storch et al. 2002; Ueda et al. 2002; Duffield 2003; Welsh et al. 2004; Reddy et al. 2006). This dynamic control of gene expression is a hallmark of the mammalian circadian clock, which is comprised of interlocking transcriptional-translational feedback loops (Lowrey and Takahashi 2004; Takahashi et al. 2008). Steady-state levels of 5\%-10\% of the mRNAs in any given tissue are rhythmic (Duffield 2003; Rey et al. 2011; Koike et al. 2012; Menet et al. 2012). Many of these genes are regulated transcriptionally, either by direct rhythmic transactivation by CLOCK/BMAL1, the central transcriptional activators of the core clock mechanism, or indirectly by other rhythmic transcription factors that are downstream from the core loop. However, many steps occur between transcriptional initiation and ultimate protein function and many, if not all, of these steps could conceivably be subject to circadian regulation.

Transcripts are capped and spliced while they are still being transcribed and then the $3^{\prime}$ ends are cleaved and polyadenylated. Each of these steps requires many accessory proteins and/or small RNAs and frequently many alternate splice forms and alternate polyadenylation sites can be chosen. RNAs are coated with RNAbinding proteins, forming ribonucleoprotein complexes and are exported to the cytoplasm (and in some cases to specific regions of the cell), where they are translated and eventually degraded. During the time in the cytoplasm, the

Editors: Paolo Sassone-Corsi, Michael W. Young, and Akhilesh B. Reddy

Additional Perspectives on Circadian Rhythms available at www.cshperspectives.org

Copyright (C) 2018 Cold Spring Harbor Laboratory Press; all rights reserved; doi: 10.1101/cshperspect.a030692

Cite this article as Cold Spring Harb Perspect Biol 2018;10:a030692 


\section{C.B. Green}

mRNAs may be deadenylated and stored in a translationally silent form, followed by later readenylation to make them translationally competent. Regulation of the protein products that result from translating these mRNAs depends on extensive regulation at many or all of these steps.

Much of the work on the mechanisms of circadian gene expression has focused on transcriptional control and the primary readouts have been steady-state mRNA levels, as a result largely of the ease of making these measurements. However, extensive evidence is accumulating that posttranscriptional control is an important mechanism for generating appropriate circadian outputs. For example, the development of methods to examine nascent transcripts (or pre-mRNAs) around the circadian cycle have revealed that many rhythmic mRNAs are not transcribed rhythmically (Koike et al. 2012; Menet et al. 2012) and mathematical modeling of these types of datasets support the idea that mRNA degradation and other posttranscriptional mechanisms must be involved in generating the rhythms in steady-state levels (Luck et al. 2014; Luck and Westermark 2016). In addition, a significant fraction of rhythmic proteins is encoded by nonrhythmic mRNAs, suggesting additional regulatory mechanisms (Reddy et al. 2006; Mauvoisin et al. 2014; Robles et al. 2014). It has also been found that the clock is quite insensitive to large fluctuations of transcription rate (Dibner et al. 2009), suggesting that posttranscriptional mechanisms may be able to buffer the system to generate reliable rhythms. Moreover, circadian rhythms can exist in red blood cells devoid of nuclei (O'Neill and Reddy 2011; O’Neill et al. 2011), showing that mechanisms beyond transcription can also drive rhythmic physiology.

This review will focus on posttranscriptional regulatory mechanisms in the circadian system in mammals. There are other excellent reviews of circadian posttranscriptional regulation in mammals and other organisms (e.g., Kojima et al. 2011; Staiger and Koster 2011; Zhang et al. 2011; Lim and Allada 2013; Kojima and Green 2015; Romanowski and Yanovsky 2015; Preussner and Heyd 2016).

\section{PROCESSING OF THE PRIMARY TRANSCRIPT}

Following transcriptional initiation, DNA-dependent RNA polymerase II ( Pol II) enters the elongation phase, proceeding down the gene to generate the nascent RNA transcript. As the newly synthesized transcript emerges from the polymerase, processing and modifications begin to occur, starting with the addition of the 7-methylguanosine cap at the $5^{\prime}$ end followed by binding by the Cap-binding complex (CBC) (reviewed in Carmody and Wente 2009). Inhibiting this process by knockdown of the methylase that generates the 7-methylguanosine (Rnmt) or the major unit of the CBC (Ncbp1) causes significant lengthening of the circadian period $(>2 \mathrm{~h}$ ) as measured by luciferase reporter under the control of the Bmall promoter in rhythmic U2OS human osteosarcoma cells (Fustin et al. 2013). The mechanism by which this lengthens the period is not known, but suggests that this first step of mRNA processing must contribute to correct periodicity.

As the transcript lengthens, any introns that are present are spliced out shortly after they emerge from Pol II by the huge ribonucleoprotein complex called the spliceosome. This step is extensively regulated and a significant fraction of genes can be alternatively spliced, generating more than one (and in some cases, many) different isoforms of the final mRNA. For example, many of the core clock genes have alternative splice forms, as was first reported for Clock (King et al. 1997) and Bmall when they were initially cloned (Ikeda and Nomura 1997).

More recently, it was reported that alternative splicing of Per2 in human keratinocytes produces an extremely short form of PER2 called PER2S (Avitabile et al. 2014). This form contains only the amino-terminal part of the normal PER2 and is lacking more than half of the protein. PER2S is unique from PER2 in that it is localized to the nucleolus. When nucleolar structure is transiently and reversibly perturbed, the PER2S is released and resets the clock as seen from synchronization of cells following such 
perturbation. This finding represents a novel mechanism for synchronization in response to nucleolar function.

The first examination of alternative splicing on a genome-wide level across the circadian cycle in mammals was performed using exon arrays to estimate splice forms from mouse liver (McGlincy et al. 2012). They found alternative splicing of many exons over the circadian day and also found changes that were influenced by fasting and feeding, suggesting that this is a mechanism used by the clock to regulate the specific isoforms of mRNAs needed for each time of day and for nutrient availability.

Several additional cases have recently been reported in which alternative transcripts generated by alternative splicing can regulate various aspects of clock function. For example, it has been found that the Opn4 gene, which encodes the nonvisual retinal photoreceptor melanop$\sin$, is alternatively spliced to generate a long and a short isoform, which differ only in their carboxy-terminal tails (Pires et al. 2009; Jagannath et al. 2015). Both isoforms form functional photopigments, but mediate different behavioral responses to light, presumably through different downstream signaling pathways resulting from the different carboxyl termini. Although both isoforms contribute to phase shifting, OPN4S is solely responsible for pupillary constriction and OPN4L regulates negative masking to light.

A particularly intriguing example of rhythmic alternative splicing is that reported for the U2af26 gene, which was shown to control PERIOD1 protein stability and the circadian clock in mice (Preussner et al. 2014). The alternative splicing changes the reading frame so the protein encodes a carboxy-terminal domain with similarity to the circadian clock protein timeless from Drosophila (dTIM). This variant containing the dTIM-like domain interacts with PER1 and destabilizes it. Mice lacking U2af26 have disruption in peripheral rhythms, arrhythmic PER protein levels, and also have rapid phase advances to shifted light. This alternative form is both rhythmic and induced acutely by light, and the authors of this paper suggest that alternative splicing of this gene is a buffering mech- anism that limits PER1 induction to prevent inappropriate phase shifts.

\section{OTHER ALTERNATE TRANSCRIPTS}

Functionally analogous to alternative splicing (although not technically "posttranscriptional”), other alternate transcripts can be generated through alternate transcription start site usage or through termination at alternate polyadenylation sites. Several examples of this type of regulation have been reported for transcripts in the clock mechanism. In genome-wide analysis of transcripts from the mouse hypothalamic suprachiasmatic nucleus (SCN; the locus of the central clock in mammals), it was noticed that a previously undescribed exon was expressed in the Cryl gene (Pembroke et al. 2015). The inclusion of this exon adds sequence to the $5^{\prime}$ end of the transcript. Both isoforms are rhythmically expressed but cycle in antiphase with each other. The function of this alternate transcript is not known.

The decision where to terminate transcription is also a highly regulated process and ChIPseq analysis of mouse liver revealed that RNA Pol II accumulates at termination sites of the Per and Cry genes, where it interacts with the PERIOD repressive complex of proteins during the first part of the repressive phase (Padmanabhan et al. 2012). The interaction of the PER complex inhibits SETX, a helicase that promotes transcription termination. As levels of the PER complex increase, this inhibition prevents normal RNA Pol II release and termination, causing the polymerase to accumulate near the termination site. Because transcription initiation and termination are linked, this loss of termination causes subsequent loss of initiation, therefore generating another negative feedback mechanism by the PER complex, but at a posttranscriptional level.

Alternative polyadenylation site usage is also used by the circadian system to posttranscriptionally regulate gene expression. The RNA-binding proteins CIRBP and RBM3 are both cold-inducible and their rhythmic expression patterns are driven by the low amplitude rhythms in body temperature. Analysis of their 


\section{C.B. Green}

binding showed that the $3^{\prime}$ UTR binding sites are enriched near polyadenylation sites. Depletion of either protein shortened the UTR and cold temperature (which increases the proteins levels) lengthened them (Liu et al. 2013). Changing the length of the $3^{\prime}$ UTR can have profound impact on mRNA levels, because this can change the presence of sites for microRNAs (miRNAs) and RNA-binding proteins that regulate mRNA export, stability, and translation. One of the RNAs bound by CIRBP is the Clock mRNA and knockdown of CIRBP causes reduced rhythmicity with low amplitude rhythms (Morf et al. 2012). In the knockout, CLOCK protein levels are low and arrhythmic and Clock mRNA was reduced in the cytoplasm but unchanged in the nucleus, suggesting that CIRBP regulates Clock mRNA nuclear export or promotes cytosol-specific decay. Interestingly, it was recently reported that the threefold rhythm of Cirbp mRNA, driven by the daily small fluctuation in body temperature, is itself posttranscriptionally generated and is the result of temperature-dependent regulation of splicing efficiency (Gotic et al. 2016). This rhythm in splicing efficiency also affects the accumulation of other mRNAs, and represents another posttranscriptional mechanism in the circadian toolbox.

\section{EXPORT FROM THE NUCLEUS}

Once the mature mRNA is generated, it must be exported from the nucleus so that it can be translated in the cytoplasm. The export process is also highly regulated and examples of clock control of this process are beginning to emerge. Evidence that rate of mRNA export contributes to the correct period length determination came unexpectedly from experiments probing the role of transmethylation of mRNA (Fustin et al. 2013). Inhibition of RNA methylation, by the global inhibitor 3-deazaadenosine or by suppression of the m6A methylase Mettl3, was found to cause prolonged nuclear retention of circadian RNAs such as Per2 and Arntl (Bmal1 mRNA), independent of transcription. This increased nuclear retention caused decreased cytoplasmic mRNA and protein levels and pro- duced long circadian periods in MEF and U2OS cells, in SCN slices and in locomotor activity in mice (when inhibitors were infused into the third ventricle near the SCN). It is unclear from these studies whether the circadian lengthening effects of methylation are caused by the slowing of RNA processing at one or more steps (capping, splicing, etc.) or whether this is a targeted effect specifically on mRNA export. However, the long periods caused by inhibition of the $\mathrm{m} 7$ capping are additive with the m6A methylase inhibition, resulting in extremely long periods of more than $30 \mathrm{~h}$, suggesting that these are independent mechanisms both contributing to period determination.

Other evidence for circadian control of nuclear export comes from the demonstration that the nuclear bodies called paraspeckles are rhythmic. Paraspeckles are thought to function to prevent some mRNAs containing specific sequences (inverted Alu repeats) from being exported from the nucleus and therefore prevent translation (Chen et al. 2008). These large ribonucleoprotein complexes are made from a long noncoding RNA called Neat 1 bound by proteins including NONO, SFPQ, RBM14, and PSPC1. In rat pituitary cells, the numbers of paraspeckles and the levels of the RNA and protein components change over the circadian day (Guillaumond et al. 2011; Torres et al. 2016). Furthermore, reporter RNAs containing the inverted Alu sequences were retained in the nucleus and released into the cytoplasm with a corresponding circadian rhythm. The disruption of paraspeckles caused loss of rhythmicity of some mRNAs, therefore showing the importance of this mechanism for regulating rhythmic expression, at least in this cell type. Interestingly, NONO, one of the components of the paraspeckles, was originally identified as a PER1-interacting protein in Rat1 fibroblasts and knockdown of this protein in cycling NIH3T3 cells or in Drosophila caused attenuation of rhythms (Brown et al. 2005). Whether this is the result of changes in paraspeckles or to other functions of NONO is not known, but together these studies support a role for nuclear RNA processing and export in generating proper rhythmicity. 


\section{TRANSLATIONAL REGULATION}

Once an mRNA is exported from the nucleus and arrives in the cytosol, numerous other regulatory mechanisms determine its fate. Some mRNAs are delivered to specific cellular locations, such as mRNAs that are transported to postsynaptic sites in neurons or to the leading edge of migrating cells for local translation. Regardless of the location, whether or not the mRNA is translated is determined by many factors, including signaling pathways that regulate translational initiation, levels, and composition of ribosomes, length of the mRNA poly(A) tails that promote circularization and ribosome initiation, the composition of RNA-binding proteins and miRNAs that are bound to the mRNA, which can determine the stability of the mRNA. Recent global analysis from proteomic and transcriptomic datasets have revealed that there is little correlation between mRNA levels and protein levels, suggesting that extensive regulation occurs after the mRNA is synthesized (Vogel and Marcotte 2012). It is clear from a number of studies that the circadian clock impacts many, if not all, of these steps in the generation of the appropriate rhythmic protein complement of the cell.

Comparison of mRNA levels with protein levels by transcriptomic and proteomic analyses of mouse liver over the circadian day has revealed poor correlation, suggesting extensive circadian control over translation and/or protein degradation (Reddy et al. 2006; Mauvoisin et al. 2014; Robles et al. 2014). However, problems with the sensitivity of the proteomic analysis only allow the most abundant proteins to be detected and, therefore, the extent of such regulation was difficult to determine conclusively from these studies.

Examination of mRNAs bound to polysomes (and therefore assumed to be actively translated) at different times of day found that transcripts that encoded ribosomal proteins were preferentially bound to polysomes at the beginning of night (Jouffe et al. 2013). This corresponds, in mice, to the beginning of the active phase and feeding phase and these mRNAs contained 5' UTR elements called 5'-terminal oli- gopyrimidine ( $5^{\prime}$-TOP) motifs, which are regulated by the mammalian target of rapamycin (mTOR) complex 1 in response to nutrient status. Translation initiation is thought to be the rate-limiting step in protein synthesis for most proteins and this begins with the recognition of the $5^{\prime}$ cap by eukaryotic initiation factor $4 \mathrm{E}$ (eIF4E; which binds as a complex with eIF4A and eIF4G). eIF4E's abundance and activity are highly regulated and one of these mechanisms is through mTOR-regulated eIF4E-BPs, which prevent eIF4E binding to eIF4G and therefore prevent the binding to the cap. Indeed, this study found that many of these translation initiation factors, the signaling pathways that regulate them, and the components of the mTOR1 complex were all under circadian control in the mouse liver.

Control of translation initiation may be a general feature of circadian clocks, because these pathways are also rhythmic in the mouse SCN and are regulated by light (Cao et al. 2008, 2010, 2011; Cao and Obrietan 2010). eIF4E-BP1 expression and phosphorylation are rhythmic in the SCN and mice lacking Eif4ebp1 entrain to phase shifts more rapidly as measured by locomotor activity and PER rhythmicity and are also resistant to desynchrony induced by constant light (Cao et al. 2013). It was also found that there was enhanced vasointestinal peptide (VIP) translation in the Eif4ebp1 knockout mice, suggesting that VIP, a critical neuropeptide in the $\mathrm{SCN}$, is under translational control by this mechanism in the SCN. Further analysis of this pathway revealed that signaling pathways that phosphorylate eIF4E are also rhythmic in the SCN and acutely induced by light (Cao et al. 2015). Knockin mice carrying a mutation (S209A) of eIF4E that cannot be phosphorylated were shown to have deficits in phase shifting and did not entrain well to non-24-h T cycles. Although the precise mechanism for these deficits are not known, phosphorylation of this site in eIF4e promotes PER1 and PER2 translation in MEFs and the S209A mutant mice also have reduced levels of PER proteins over the circadian cycle and following a light pulse.

Another intriguing link between the mTOR pathway and the circadian clock comes from the 


\section{C.B. Green}

demonstration that the core clock transcriptional activator BMAL1 has a surprising cytosolic role as a translation factor (Lipton et al. 2015). It was shown that BMAL1 can be phosphorylated by the mTOR-effector S6K1 and, when phosphorylated, BMAL1 can associate with the translational machinery and broadly stimulate protein synthesis. These findings directly connect the core circadian timing machinery to the control of protein production.

More extensive analysis of rhythmic translation comes from ribosomal profiling methods in mouse liver and in rhythmic U2OS cells with high temporal and nucleotide resolution (Jang et al. 2015; Janich et al. 2015). In the mouse liver study (Janich et al. 2015), 150 "high-confidence" mRNAs were identified that were not rhythmic in their steady-state levels but were rhythmically translated and a somewhat smaller set with similar profiles were identified in the human U2OS cells. Together, these studies suggest that the circadian clock controls translation through a number of different mechanisms and this contributes to the final rhythmic protein makeup of the cell.

Mathematical modeling of the effect of different PER translation kinetics suggested that regulation of this step could be important for generating self-sustained oscillations with characteristic period, amplitude, and phase lag (the time delays between Per mRNA and PER protein) (Nieto et al. 2015). However, both ribosome profiling studies found that the core clock genes had matching mRNA and ribosome profiles, suggesting that the lag between mRNA and protein peaks over the circadian cycle is not the result of translational control. However, upstream open reading frames ( $\mathrm{uORFs}$ ) were identified in several clock genes in both cell types. Because active uORFs usually decrease translation of the downstream main ORF, the presence of these suggest that these mRNAs may be subject to translational control under some circumstances, for example in response to environmental signals.

Additionally, a number of studies have implicated various RNA-binding proteins and miRNAs in translational regulation of the core clock mRNAs and various circadian output
mRNAs. The RNA-binding protein AUF (also known as hnRNP D) is rhythmic and was shown to bind rhythmically to Cryl $3^{\prime}$ UTR in antiphase with peak Cry1 mRNA levels, then associates with the translation initiation factor eIF3B, recruiting the $40 \mathrm{~S}$ subunit to $5^{\prime}$ end, leading to time-dependent translation of CRY1 (Lee et al. 2014). Another protein, LARK, was shown to bind rhythmically to the Perl $3^{\prime}$ UTR and increases PER1 protein expression, most likely through translational regulation (Kojima et al. 2003; Kojima et al. 2007). LARK protein levels (but not mRNA levels) cycle in the SCN and knockdown or overexpression of this gene in cycling cells produces short or long periods, respectively. Per1 undergoes both cap-dependent and IRES-mediated translation and the protein hnRNP Q has been reported to control timedependent IRES-mediated translation of Perl through rhythmic interaction with the Perl mRNA (Lee et al. 2012a,b) and to regulate the translation of AANAT, the rate-limiting enzyme in melatonin production in the pineal gland (Kim et al. 2007).

Another potential role for translational regulation is suggested by the phenotypes of mice lacking the genes for the translational repressor proteins, Fmr1 (encodes FMRP) and Fxr2 (Zhang et al. 2008). In mice, knockout of either Fmr1 or Fxr2 have short periods and Fmr1/Fxr2 double knockouts (both homo- and heterozygous) are arrhythmic. The mechanism behind this is not known and although they did see changes in several core clock gene mRNA levels in liver; this study did not examine the levels of these proteins, so no conclusion about translational control can be drawn.

Several RNA-binding proteins have also been identified that contribute to the circadian regulation of mRNA half-life, which can indirectly impact translation. These include AUF1, which modulates Cryl stability (Woo et al. 2010), polypyrimidine tract-binding protein (PTB), which binds to Per2 $3^{\prime}$ UTR and regulates its stability (Woo et al. 2009), KSRP, which regulates the stability of Per2 (Chou et al. 2015), and AUF1 and hnRNP K, which both interact with Per3 3' UTR but have opposite effects, with hnRNP K stabilizing the mRNA and AUF1 de- 
stabilizing it (Kim et al. 2015). In addition, hnRNP Q, hnRNP R, and hnRNP L have all been shown to be expressed rhythmically in the pineal gland and induce the degradation of the mRNA encoding AANAT (Kim et al. 2005, 2007).

\section{miRNAs}

In addition to the many RNA-binding proteins that regulate translation and mRNA decay, miRNAs also play a critical role. And they too appear to play a role in shaping the circadian proteome. A number of miRNAs have been implicated in the regulation of specific mRNAs, including the highly abundant, liver-specific miRNA-122, which is synthesized rhythmically under the control of the circadian transcriptional repressor Rev-erb $\alpha$, although the levels of the mature form are not rhythmic because of its long half-life. Knockdown of this miRNA results in both increases and decreases of hundreds of mRNAs, a large fraction of which are rhythmic. These include mRNAs encoding proteins in many important metabolic pathways in the liver, including lipid and cholesterol metabolism (Gatfield et al. 2009). Among these mRNA targets is the mRNA encoding Nocturnin, an enzyme that removes poly(A) tails from mRNAs and is itself involved in circadian posttranscriptional regulation (Kojima et al. 2010).

There are a number of other examples of specific miRNAs that are involved in circadian rhythms, including the brain-specific miRNAs miR-219 and miR-132, which appear to contribute to both light-induced clock resetting and period length regulation (Cheng et al. 2007; Alvarez-Saavedra et al. 2011), miR-155 in macrophages, which targets the $3^{\prime}$ UTR of BMAL1 (Curtis et al. 2015), miR-185, which oscillates in antiphase to CRY1 levels and controls Cry 1 mRNA translation in NIH3T3 cells (Lee et al. 2013).

Despite these examples of specific miRNAs regulating core clock genes, the effects of miRNAs on the clock is less clear when global miRNA biogenesis is prevented by Dicer knockdown. In liver, using an inducible Dicer knockdown system, extensive changes in rhythmic
mRNA profiles are seen, but these changes are largely modulatory, such as changes in phase or amplitude (Du et al. 2014). The core clock gene mRNAs were largely not affected by miRNA loss except for Per2, which showed a twofold increase in amplitude. Liver explants from these mice had slight period lengthening. In contrast, knockdown of Dicer in NIH3T3 cells increased the Cryl 3' UTR reporter activity (Lee et al. 2013) and Dicer knockdown in mouse embryo fibroblast cells produced short periods, which was attributed to faster Per 1 and Per 2 translation (Chen et al. 2013). Since such different results have been noted in these different cell types, it may be that miRNAs are important for tissue-specific tuning and shaping of circadian gene-expression patterns, and perhaps could contribute to known tissue-specific differences in phases and free-running period lengths (Yoo et al. 2004).

\section{POLY(A) TAIL LENGTH}

One of the first observations of circadian posttranscriptional control in mammals was the observation that the arginine vasopressin (AVP) mRNA changed size over the circadian day in the SCN (Robinson et al. 1988). This change in size was shown to be caused by changes in the length of the poly(A) tails at the $3^{\prime}$ ends of the mRNA. Long poly(A) tails are added to mRNAs in the nucleus following transcription termination and shortening and removal of the tails by enzymes called deadenylases is a critical step in degradation of the mRNA and is regulated by RNA-binding proteins and miRNAs (Eckmann et al. 2011). Although it was originally thought that shortening the tails determined decay, it is now known that some mRNAs can exist in short-tailed forms and be readenylated in the cytoplasm by cytoplasmic poly(A) polymerases (reviewed in Weill et al. 2012). Circadian profiling of poly(A) tail lengths from mouse liver samples revealed that hundreds of mRNAs have rhythmic poly(A) tail lengths and that these lengths correlate well with protein levels encoded by those mRNAs, even when the mRNAs were not rhythmic at the steady-state level (Kojima et al. 2012). Proteins implicated in 


\section{C.B. Green}

cytoplasmic polyadenylation were also found to be rhythmic in the mouse liver and one of these, $\mathrm{CPEB} 2$, was found to regulate rhythmic poly $(\mathrm{A})$ addition for at least some mRNAs. Although poly(A) tail length has not been found to strongly correlate with translatability in general, it can regulate translation in certain cases were transcriptional control is not useful such as in the early embryo or in the postsynaptic region of neurons (Subtelny et al. 2014). The strong correlation between poly (A) tail length and protein rhythms in the mouse liver suggest that the circadian system is another case in which this mechanism is used.

There are at least eight deadenylases in mammals (Goldstrohm and Wickens 2008) and several of them show low amplitude rhythms, peaking in the early day (Kojima et al. 2012). However, one of them, the deadenylase called Nocturnin (Baggs and Green 2003; Garbarino-Pico et al. 2007), shows very high amplitude rhythms, peaking at night (Green and Besharse 1996; Wang et al. 2001; Stubblefield et al. 2012; Godwin et al. 2013). Mice lacking Nocturnin have a strong metabolic phenotype, with protection from obesity on a high-fat diet and alterations in many circadian metabolic pathways (Green et al. 2007; Douris and Green 2008; Douris et al. 2011; Stubblefield et al. 2012). Comparison of poly(A) tail lengths, using an approach similar to the one described above for the circadian analysis, revealed mRNAs with longer tails in the Nocturnin knockout liver and these represent candidates for Nocturnin target mRNAs (Kojima et al. 2015). Surprisingly, these mRNAs showed little overlap with the set of mRNAs with cycling poly(A) tail lengths or with the known rhythmic mRNAs, suggesting that the role of Nocturnin is not to generate rhythmic tails. However, the assay used to identify the poly(A) tail lengths in both experiments (differential elution from oligo[dT] beads) could not reliably detect mRNAs that are present at low copy number. More work with more sensitive assays is needed to define the role for Nocturnin in the circadian clock.

Finally, the role of cytoplasmic granules such as processing bodies (P-bodies) in regulating circadian protein expression has not been carefully examined, but they are likely to be involved. These bodies store mRNAs that are not being translated (such as those that have been deadenylated) until they are either degraded or placed back into the translatable pool (Decker and Parker 2012). Recent ribosome profiling of U2OS cells revealed that the LSM1 protein, a critical component of P-bodies is rhythmically translated and subsequent experiments showed that cytoplasmic P-body formation is rhythmic in these cells (Jang et al. 2015). This finding provides further evidence that the circadian clock governs the fate of mRNAs in the cytoplasm in previously unappreciated ways.

\section{CONCLUDING REMARKS}

Circadian rhythms regulate critical functions throughout the mammalian body, including biochemical and metabolic pathways, higher order cell and tissue functions, and complex behavior. These functions are generated by the rhythmic patterns of protein function (not mRNA levels) and the emerging data discussed here indicate that posttranscriptional regulatory mechanisms are not simply "refinements" of transcriptional regulation, but are critical for generating the proper rhythmic protein outputs of the clock. Despite these exciting new insights, it is clear that there is much more to be learned about how the clock uses posttranscriptional mechanisms to drive rhythmic physiology.

\section{ACKNOWLEDGMENTS}

I thank the National Institutes of Health (NIH) for funding support (R01 GM112991, R01 GM111387, and R01 AG045795).

\section{REFERENCES}

\footnotetext{
Akhtar RA, Reddy AB, Maywood ES, Clayton JD, King VM, Smith AG, Gant TW, Hastings MH, Kyriacou CP. 2002. Circadian cycling of the mouse liver transcriptome, as revealed by cDNA microarray, is driven by the suprachiasmatic nucleus. Curr Biol 12: 540-550.

Alvarez-Saavedra M, Antoun G, Yanagiya A, Oliva-Hernandez R, Cornejo-Palma D, Perez-Iratxeta C, Sonenberg N, Cheng HY. 2011. miRNA-132 orchestrates chromatin remodeling and translational control of the circadian clock Hum Mol Genet 20: 731-751.
} 
Avitabile D, Genovese L, Ponti D, Ranieri D, Raffa S, Calogero A, Torrisi MR. 2014. Nucleolar localization and circadian regulation of Per2S, a novel splicing variant of the Period 2 gene. Cell Mol Life Sci 71: 2547-2559.

Baggs JE, Green CB. 2003. Nocturnin, a deadenylase in Xenopus laevis retina: A mechanism for posttranscriptional control of circadian-related mRNA. Curr Biol 13: 189198.

Brown SA, Ripperger J, Kadener S, Fleury-Olela F, Vilbois F, Rosbash M, Schibler U. 2005. PERIOD1-associated proteins modulate the negative limb of the mammalian circadian oscillator. Science 308: 693-696.

Cao R, Obrietan K. 2010. mTOR signaling and entrainment of the mammalian circadian clock. Mol Cell Pharmacol 2: $125-130$.

Cao R, Lee B, Cho HY, Saklayen S, Obrietan K. 2008. Photic regulation of the mTOR signaling pathway in the suprachiasmatic circadian clock. Mol Cell Neurosci 38: 312 324.

Cao R, Li A, Cho HY, Lee B, Obrietan K. 2010. Mammalian target of rapamycin signaling modulates photic entrainment of the suprachiasmatic circadian clock. J Neurosci 30: 6302-6314.

Cao R, Anderson FE, Jung YJ, Dziema H, Obrietan K. 2011. Circadian regulation of mammalian target of rapamycin signaling in the mouse suprachiasmatic nucleus. Neuroscience 181: 79-88.

Cao R, Robinson B, Xu H, Gkogkas C, Khoutorsky A, Alain T, Yanagiya A, Nevarko T, Liu AC, Amir S, et al. 2013 Translational control of entrainment and synchrony of the suprachiasmatic circadian clock by mTOR/4E-BP1 signaling. Neuron 79: 712-724.

Cao R, Gkogkas CG, de Zavalia N, Blum ID, Yanagiya A, Tsukumo Y, Xu H, Lee C, Storch KF, Liu AC, et al. 2015. Light-regulated translational control of circadian behavior by eIF4E phosphorylation. Nat Neurosci 18: 855-862.

Carmody SR, Wente SR. 2009. mRNA nuclear export at a glance. J Cell Sci 122: 1933-1937.

Chen LL, DeCerbo JN, Carmichael GG. 2008. Alu elementmediated gene silencing. EMBO J 27: 1694-1705.

Chen R, D'Alessandro M, Lee C. 2013. miRNAs are required for generating a time delay critical for the circadian oscillator. Curr Biol 23: 1959-1968.

Cheng HY, Papp JW, Varlamova O, Dziema H, Russell B, Curfman JP, Nakazawa T, Shimizu K, Okamura H, Impey S, et al. 2007. microRNA modulation of circadian-clock period and entrainment. Neuron 54: 813-829.

Chou CF, Zhu X, Lin YY, Gamble KL, Garvey WT, Chen CY 2015. KSRP is critical in governing hepatic lipid metabolism through controlling Per2 expression. J Lipid Res 56: 227-240.

Curtis AM, Fagundes CT, Yang G, Palsson-McDermott EM, Wochal P, McGettrick AF, Foley NH, Early JO, Chen L, Zhang H, et al. 2015. Circadian control of innate immunity in macrophages by miR-155 targeting Bmall. Proc Natl Acad Sci 112: 7231-7236.

Decker CJ, Parker R. 2012. P-bodies and stress granules: Possible roles in the control of translation and mRNA degradation. Cold Spring Harb Perspect Biol 4: a012286.

Dibner C, Sage D, Unser M, Bauer C, d'Eysmond T, Naef F, Schibler U. 2009. Circadian gene expression is resilient to large fluctuations in overall transcription rates. $E M B O J$ 28: $123-134$.

Douris N, Green CB. 2008. NOC out the fat: A short review of the circadian deadenylase Nocturnin. Ann Med 40: $622-626$.

Douris N, Kojima S, Pan X, Lerch-Gaggl AF, Duong SQ, Hussain MM, Green CB. 2011. Nocturnin regulates circadian trafficking of dietary lipid in intestinal enterocytes. Curr Biol 21: 1347-1355.

Du NH, Arpat AB, De Matos M, Gatfield D. 2014. MicroRNAs shape circadian hepatic gene expression on a transcriptome-wide scale. eLife 3: $\mathrm{e} 02510$.

Duffield GE. 2003. DNA microarray analyses of circadian timing: The genomic basis of biological time. J Neuroendocrinol 15: 991-1002.

Eckmann CR, Rammelt C, Wahle E. 2011. Control of poly(A) tail length. Wiley Interdiscip Rev RNA 2: 348361.

Fustin JM, Doi M, Yamaguchi Y, Hida H, Nishimura S, Yoshida M, Isagawa T, Morioka MS, Kakeya H, Manabe I, et al. 2013. RNA-methylation-dependent RNA processing controls the speed of the circadian clock. Cell 155: 793-806.

Garbarino-Pico E, Niu S, Rollag MD, Strayer CA, Besharse JC, Green CB. 2007. Immediate early response of the circadian polyA ribonuclease nocturnin to two extracellular stimuli. RNA 13: 745-755.

Gatfield D, Le Martelot G, Vejnar CE, Gerlach D, Schaad O, Fleury-Olela F, Ruskeepaa AL, Oresic M, Esau CC, Zdobnov EM, et al. 2009. Integration of microRNA miR-122 in hepatic circadian gene expression. Genes Dev 23: 1313-1326.

Godwin AR, Kojima S, Green CB, Wilusz J. 2013. Kiss your tail goodbye: The role of PARN, Nocturnin, and Angel deadenylases in mRNA biology. Biochim Biophys Acta 1829: $571-579$.

Goldstrohm AC, Wickens M. 2008. Multifunctional deadenylase complexes diversify mRNA control. Nat Rev Mol Cell Biol 9: 337-344.

Gotic I, Omidi S, Fleury-Olela F, Molina N, Naef F, Schibler U. 2016. Temperature regulates splicing efficiency of the cold-inducible RNA-binding protein gene Cirbp. Genes Dev 30: 2005-2017.

Green CB, Besharse JB. 1996. Identification of a novel vertebrate circadian clock-regulated gene encoding the protein nocturnin. Proc Natl Acad Sci 93: 14884-14888.

Green CB, Douris N, Kojima S, Strayer CA, Fogerty J, Lourim D, Keller SR, Besharse JC. 2007. Loss of Nocturnin, a circadian deadenylase, confers resistance to hepatic steatosis and diet-induced obesity. Proc Natl Acad Sci 104: 9888-9893.

Guillaumond F, Boyer B, Becquet D, Guillen S, Kuhn L, Garin J, Belghazi M, Bosler O, Franc JL, Francois-Bellan AM. 2011. Chromatin remodeling as a mechanism for circadian prolactin transcription: Rhythmic NONO and SFPQ recruitment to HLTF. FASEB J 25: 2740-2756.

Ikeda M, Nomura M. 1997. cDNA cloning and tissue-specific expression of a novel basic helix-loop-helix/PAS protein (BALM1) and identification of alternatively spliced variants with alternative translation initiation site usage. Biochem Biophys Res Commun 233: 258-264. 


\section{C.B. Green}

Jagannath A, Hughes S, Abdelgany A, Pothecary CA, D Pretoro S, Pires SS, Vachtsevanos A, Pilorz V, Brown LA, Hossbach M, et al. 2015. Isoforms of melanopsin mediate different behavioral responses to light. Curr Biol 25: 2430-2434.

Jang C, Lahens NF, Hogenesch JB, Sehgal A. 2015. Ribosome profiling reveals an important role for translational control in circadian gene expression. Genome Res 25: 18361847.

Janich P, Arpat AB, Castelo-Szekely V, Lopes M, Gatfield D. 2015. Ribosome profiling reveals the rhythmic liver translatome and circadian clock regulation by upstream open reading frames. Genome Res 25: 1848-1859.

Jouffe C, Cretenet G, Symul L, Martin E, Atger F, Naef F, Gachon F. 2013. The circadian clock coordinates ribosome biogenesis. PLoS Biol 11: e1001455.

Kim TD, Kim JS, Kim JH, Myung J, Chae HD, Woo KC, Jang SK, Koh DS, Kim KT. 2005. Rhythmic serotonin $N$-acetyltransferase mRNA degradation is essential for the maintenance of its circadian oscillation. Mol Cell Biol 25: $3232-3246$.

Kim TD, Woo KC, Cho S, Ha DC, Jang SK, Kim KT. 2007. Rhythmic control of AANAT translation by hnRNP Q in circadian melatonin production. Genes Dev 21: 797-810.

Kim SH, Lee KH, Kim DY, Kwak E, Kim S, Kim KT. 2015. Rhythmic control of mRNA stability modulates circadian amplitude of mouse Period3 mRNA. J Neurochem 132: $642-656$.

King DP, Zhao Y, Sangoram AM, Wilsbacher LD, Tanaka M, Antoch MP, Steeves TD, Vitaterna MH, Kornhauser JM, Lowrey PL, et al. 1997. Positional cloning of the mouse circadian Clock gene. Cell 89: 641-653.

Koike N, Yoo SH, Huang HC, Kumar V, Lee C, Kim TK, Takahashi JS. 2012. Transcriptional architecture and chromatin landscape of the core circadian clock in mammals. Science 338: 349-354.

Kojima S, Green CB. 2015. Circadian genomics reveal a role for post-transcriptional regulation in mammals. Biochemistry 54: 124-133.

Kojima S, Hirose M, Tokunaga K, Sakaki Y, Tei H. 2003. Structural and functional analysis of $3^{\prime}$ untranslated region of mouse Period 1 mRNA. Biochem Biophys Res Commun 301: 1-7.

Kojima S, Matsumoto K, Hirose M, Shimada M, Nagano M, Shigeyoshi Y, Hoshino S, Ui-Tei K, Saigo K, Green CB, et al. 2007. LARK activates posttranscriptional expression of an essential mammalian clock protein, PERIOD1. Proc Natl Acad Sci 104: 1859-1864.

Kojima S, Gatfield D, Esau CC, Green CB. 2010. MicroRNA122 modulates the rhythmic expression profile of the circadian deadenylase Nocturnin in mouse liver. PLoS ONE 5: e11264.

Kojima S, Shingle DL, Green CB. 2011. Post-transcriptional control of circadian rhythms. J Cell Sci 124: 311-320.

Kojima S, Sher-Chen EL, Green CB. 2012. Circadian control of mRNA polyadenylation dynamics regulates rhythmic protein expression. Genes Dev 26: 2724-2736.

Kojima S, Gendreau KL, Sher-Chen EL, Gao P, Green CB. 2015. Changes in poly(A) tail length dynamics from the loss of the circadian deadenylase Nocturnin. Sci Rep 5: 17059 .
Lee KH, Kim SH, Kim DY, Kim S, Kim KT. 2012a. Internal ribosomal entry site-mediated translation is important for rhythmic PERIOD1 expression. PLoS ONE 7: e37936.

Lee KH, Woo KC, Kim DY, Kim TD, Shin J, Park SM, Jang SK, Kim KT. 2012b. Rhythmic interaction between Period 1 mRNA and hnRNP Q leads to circadian time-dependent translation. Mol Cell Biol 32: 717-728.

Lee KH, Kim SH, Lee HR, Kim W, Kim DY, Shin JC, Yoo SH, Kim KT. 2013. MicroRNA-185 oscillation controls circadian amplitude of mouse Cryptochrome 1 via translational regulation. Mol Biol Cell 24: 2248-2255.

Lee KH, Kim SH, Kim HJ, Kim W, Lee HR, Jung Y, Choi JH, Hong KY, Jang SK, Kim KT. 2014. AUF1 contributes to Cryptochrome1 mRNA degradation and rhythmic translation. Nucleic Acids Res 42: 3590-3606.

Lim C, Allada R. 2013. Emerging roles for post-transcriptional regulation in circadian clocks. Nat Neurosci 16: $1544-1550$.

Lipton JO, Yuan ED, Boyle LM, Ebrahimi-Fakhari D, Kwiatkowski E, Nathan A, Guttler T, Davis F, Asara JM, Sahin M. 2015. The circadian protein BMAL1 regulates translation in response to S6K1-mediated phosphorylation. Cell 161: 1138-1151.

Liu Y, Hu W, Murakawa Y, Yin J, Wang G, Landthaler M, Yan J. 2013. Cold-induced RNA-binding proteins regulate circadian gene expression by controlling alternative polyadenylation. Sci Rep 3: 2054.

Lowrey PL, Takahashi JS. 2004. Mammalian circadian biology: Elucidating genome-wide levels of temporal organization. Annu Rev Genomics Hum Genet 5: 407-441.

Luck S, Westermark PO. 2016. Circadian mRNA expression: Insights from modeling and transcriptomics. Cell Mol Life Sci 73: 497-521.

Luck S, Thurley K, Thaben PF, Westermark PO. 2014. Rhythmic degradation explains and unifies circadian transcriptome and proteome data. Cell Rep 9: 741-751.

Mauvoisin D, Wang J, Jouffe C, Martin E, Atger F, Waridel P, Quadroni M, Gachon F, Naef F. 2014. Circadian clockdependent and -independent rhythmic proteomes implement distinct diurnal functions in mouse liver. Proc Natl Acad Sci 111: 167-172.

McGlincy NJ, Valomon A, Chesham JE, Maywood ES, Hastings MH, Ule J. 2012. Regulation of alternative splicing by the circadian clock and food related cues. Genome Biol 13: R54.

Menet JS, Rodriguez J, Abruzzi KC, Rosbash M. 2012. Nascent-Seq reveals novel features of mouse circadian transcriptional regulation. eLife 1: e00011.

Morf J, Rey G, Schneider K, Stratmann M, Fujita J, Naef F, Schibler U. 2012. Cold-inducible RNA-binding protein modulates circadian gene expression posttranscriptionally. Science 338: $379-383$.

Nieto PS, Revelli JA, Garbarino-Pico E, Condat CA, Guido ME, Tamarit FA. 2015. Effects of different per translational kinetics on the dynamics of a core circadian clock model. PLOS ONE 10: e0115067.

O’Neill JS, Reddy AB. 2011. Circadian clocks in human red blood cells. Nature 469: 498-503.

O'Neill JS, van Ooijen G, Dixon LE, Troein C, Corellou F, Bouget FY, Reddy AB, Millar AJ. 2011. Circadian rhythms 
persist without transcription in a eukaryote. Nature 469: 554-558.

Padmanabhan K, Robles MS, Westerling T, Weitz CJ. 2012. Feedback regulation of transcriptional termination by the mammalian circadian clock PERIOD complex. Science 337: 599-602.

Panda S, Antoch MP, Miller BH, Su AI, Schook AB, Straume M, Schultz PG, Kay SA, Takahashi JS, Hogenesch JB. 2002. Coordinated transcription of key pathways in the mouse by the circadian clock. Cell 109: 307-320.

Pembroke WG, Babbs A, Davies KE, Ponting CP, Oliver PL. 2015. Temporal transcriptomics suggest that twin-peaking genes reset the clock. eLife 4: e10518.

Pires SS, Hughes S, Turton M, Melyan Z, Peirson SN, Zheng L, Kosmaoglou M, Bellingham J, Cheetham ME, Lucas RJ, et al. 2009. Differential expression of two distinct functional isoforms of melanopsin (Opn4) in the mammalian retina. J Neurosci 29: 12332-12342.

Pittendrigh CS. 1981a. Circadian systems: Entrainment. In Handbook of behavioral neurobiology, Vol 4: Biological rhythms (ed. Aschoff J), pp. 95-124. Plenum, New York.

Pittendrigh C. 1981b. Circadian systems: General perspective. In Handbook of behavioral neurobiology, Vol 4: Biological rhythms (ed. Aschoff J), pp. 57-80. Plenum, New York.

Preussner M, Heyd F. 2016. Post-transcriptional control of the mammalian circadian clock: Implications for health and disease. Pflugers Arch 468: 983-991.

Preussner M, Wilhelmi I, Schultz AS, Finkernagel F, Michel M, Moroy T, Heyd F. 2014. Rhythmic U2af26 alternative splicing controls PERIOD1 stability and the circadian clock in mice. Mol Cell 54: 651-662.

Reddy AB, Karp NA, Maywood ES, Sage EA, Deery M, O'Neill JS, Wong GK, Chesham J, Odell M, Lilley KS, et al. 2006. Circadian orchestration of the hepatic proteome. Curr Biol 16: 1107-1115.

Rey G, Cesbron F, Rougemont J, Reinke H, Brunner M, Naef F. 2011. Genome-wide and phase-specific DNA-binding rhythms of BMAL1 control circadian output functions in mouse liver. PLoS Biol 9: e1000595.

Robinson BG, Frim DM, Schwartz WJ, Majzoub JA. 1988. Vasopressin mRNA in the suprachiasmatic nuclei: Daily regulation of polyadenylate tail length. Science 241: 342344.

Robles MS, Cox J, Mann M. 2014. In-vivo quantitative proteomics reveals a key contribution of post-transcriptional mechanisms to the circadian regulation of liver metabolism. PLoS Genet 10: e1004047.

Romanowski A, Yanovsky MJ. 2015. Circadian rhythms and post-transcriptional regulation in higher plants. Front Plant Sci 6: 437.

Staiger D, Koster T. 2011. Spotlight on post-transcriptional control in the circadian system. Cell Mol Life Sci 68: 7183

Storch K, Lipan O, Leykin I, Viswanathan N, Davis F, Wong W, Weitz C. 2002. Extensive and divergent circadian gene expression in liver and heart. Nature 417: 78-83.
Stubblefield JJ, Terrien J, Green CB. 2012. Nocturnin: At the crossroads of clocks and metabolism. Trends Endocrinol Metab 23: 326-333.

Subtelny AO, Eichhorn SW, Chen GR, Sive H, Bartel DP. 2014. Poly(A)-tail profiling reveals an embryonic switch in translational control. Nature 508: 66-71.

Takahashi JS, Hong HK, Ko CH, McDearmon EL. 2008. The genetics of mammalian circadian order and disorder: Implications for physiology and disease. Nat Rev Genet 9: 764-775.

Torres M, Becquet D, Blanchard MP, Guillen S, Boyer B, Moreno M, Franc JL, Francois-Bellan AM. 2016. Circadian RNA expression elicited by $3^{\prime}$-UTR IRAlu-paraspeckle associated elements. eLife 5: e14837.

Ueda HR, Chen W, Adachi A, Wakamatsu H, Hayashi S, Takasugi T, Nagano M, Nakahama K, Suzuki Y, Sugano S, et al. 2002. A transcription factor response element for gene expression during circadian night. Nature 418: $534-539$.

Vogel C, Marcotte EM. 2012. Insights into the regulation of protein abundance from proteomic and transcriptomic analyses. Nat Rev Genet 13: 227-232.

Wang Y, Osterbur DL, Megaw PL, Tosini G, Fukuhara C, Green CB, Besharse JC. 2001. Rhythmic expression of Nocturnin mRNA in multiple tissues of the mouse. BMC Dev Biol 1: 9.

Weill L, Belloc E, Bava FA, Mendez R. 2012. Translational control by changes in poly(A) tail length: Recycling mRNAs. Nat Struct Mol Biol 19: 577-585.

Welsh DK, Yoo SH, Liu AC, Takahashi JS, Kay SA. 2004. Bioluminescence imaging of individual fibroblasts reveals persistent, independently phased circadian rhythms of clock gene expression. Curr Biol 14: 22892295.

Woo KC, Kim TD, Lee KH, Kim DY, Kim W, Lee KY, Kim KT. 2009. Mouse period 2 mRNA circadian oscillation is modulated by PTB-mediated rhythmic mRNA degradation. Nucleic Acids Res 37: 26-37.

Woo KC, Ha DC, Lee KH, Kim DY, Kim TD, Kim KT. 2010. Circadian amplitude of cryptochrome 1 is modulated by mRNA stability regulation via cytoplasmic hnRNP D oscillation. Mol Cell Biol 30: 197-205.

Yoo SH, Yamazaki S, Lowrey PL, Shimomura K, Ko CH, Buhr ED, Siepka SM, Hong HK, Oh WJ, Yoo OJ, et al. 2004. PERIOD2::LUCIFERASE real-time reporting of circadian dynamics reveals persistent circadian oscillations in mouse peripheral tissues. Proc Natl Acad Sci 101: $5339-5346$

Zhang J, Fang Z, Jud C, Vansteensel MJ, Kaasik K, Lee CC, Albrecht U, Tamanini F, Meijer JH, Oostra BA, et al. 2008. Fragile X-related proteins regulate mammalian circadian behavioral rhythms. Am J Hum Genet 83: 43-52.

Zhang L, Weng W, Guo J. 2011. Posttranscriptional mechanisms in controlling eukaryotic circadian rhythms. FEBS Lett 585: 1400-1405. 


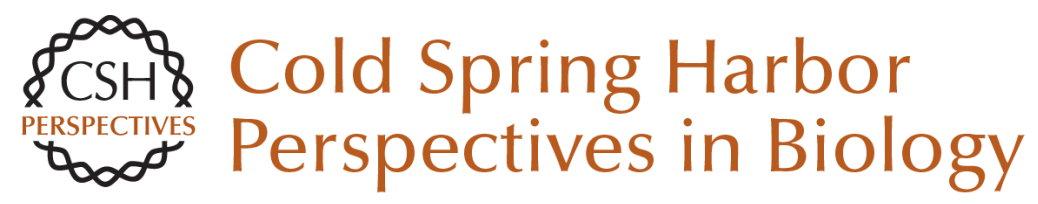

\section{Circadian Posttranscriptional Regulatory Mechanisms in Mammals}

Carla B. Green

Cold Spring Harb Perspect Biol 2018; doi: 10.1101/cshperspect.a030692 originally published online August 4, 2017

\section{Subject Collection Circadian Rhythms}

Circadian Posttranscriptional Regulatory

Mechanisms in Mammals Carla B. Green

Design Principles of Phosphorylation-Dependent Timekeeping in Eukaryotic Circadian Clocks Koji L. Ode and Hiroki R. Ueda

Interplay between Microbes and the Circadian Clock

Paola Tognini, Mari Murakami and Paolo Sassone-Corsi

\section{A 50-Year Personal Journey: Location, Gene}

Expression, and Circadian Rhythms Michael Rosbash

Regulating the Suprachiasmatic Nucleus (SCN)

Circadian Clockwork: Interplay between

Cell-Autonomous and Circuit-Level Mechanisms Erik D. Herzog, Tracey Hermanstyne, Nicola J. Smyllie, et al.

Systems Chronobiology: Global Analysis of Gene Regulation in a 24-Hour Periodic World Jérôme Mermet, Jake Yeung and Felix Naef
Coordination between Differentially Regulated Circadian Clocks Generates Rhythmic Behavior Deniz Top and Michael W. Young

Introduction to Chronobiology Sandra J. Kuhlman, L. Michon Craig and Jeanne F. Duffy

Cellular Timekeeping: It's Redox o'Clock Nikolay B. Milev, Sue-Goo Rhee and Akhilesh B. Reddy

Molecular Mechanisms of Sleep Homeostasis in Flies and Mammals Ravi Allada, Chiara Cirelli and Amita Sehgal

Membrane Currents, Gene Expression, and Circadian Clocks Charles N. Allen, Michael N. Nitabach and Christopher S. Colwell

The Plant Circadian Clock: From a Simple Timekeeper to a Complex Developmental Manager Sabrina E. Sanchez and Steve A. Kay

For additional articles in this collection, see http://cshperspectives.cshlp.org/cgi/collection/

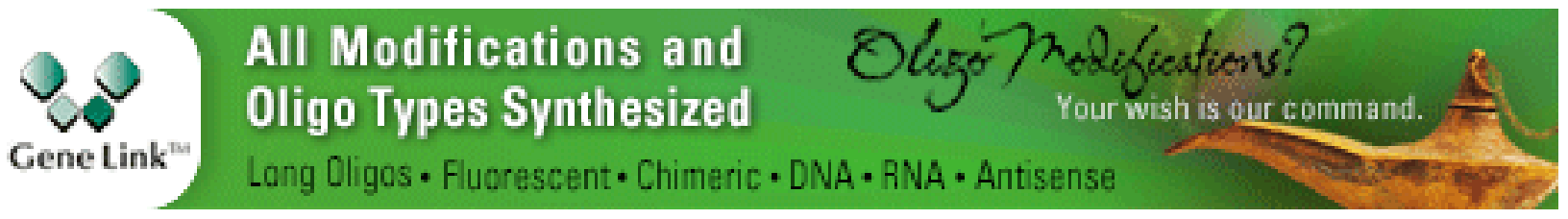

